\title{
A SCREENING FOR ANTIOXIDANT SPECIES WITH PHOTO-PROTECTOR ACTIVITIES AT THE ZONGO VALLEY (BOLIVIA)
}

\section{Sandra L. Ibáñez-Calero and Kelly E. Loayza Afonso}

\begin{abstract}
Eleven plants were collected at the Zongo Valley to evaluate their antioxidant and photo-protector properties. In this paper we report a strong correlation between high antioxidant activity and strong UV-A and/or UV-B absorptions. The most active species, tested at $10 \mu \mathrm{g} / \mathrm{ml}$ with the DPPH assay, were Fuchsia boliviana (leaves), Baccharis pentlandii (flowers), Rubus floribundus (fruits), Fuchsia boliviana (flowers and fruits) and Brachyotum microdon (flowers). All the mentioned species have important UV- B and/or UV-A absorptions. This DPPH/UV technique could be used to preliminary screen vegetable samples and to select those with DPPH values above $83 \%$ and strong UV-A and/or UV-B absorptions. The chosen samples can then be evaluated with other more expensive in vitro assay (TEAC, ABTS or FRAP) to finally confirm their activities with the in vivo test. To our knowledge, this is the first time that the antioxidant properties of Distichia muscoides, Souroubea fragilis, Brachyotum microdon, Monnina bridgesii, Baccharis pentlandii, Thibaudia crenulata, Siphocampylus tupaeformis, Cobaea scandens, Fuchsia boliviana and Rubus floribundus are reported. In addition, this is the first time that Siphocampylus tupaeformis and Thibaudia crenulata are presented in a publication as well as the study of their photo-protector and antioxidant properties.

Keywords: Zongo Valley, Antioxidant Activity, Photo-Protector Property, UV-A and/or UV-B Absorption, Distichia muscoides, Souroubea fragilis, Brachyotum microdon, Monnina bridgesii, Baccharis pentlandii, Thibaudia crenulata, Siphocampylus tupaeformis, Cobaea scandens, Fuchsia boliviana, Rumex acetocella and Rubus floribundus.
\end{abstract}

DOI: 10.23881/idupbo.019.1-2i 